\title{
Case Report: \\ Obstructive Sleep Apnea and Lhermitte's Sign Following Chemoradiation in Head and Neck Cancer
}

\author{
ALI M. ALI, M.D.*; PIERRE Y. MARCY, Ph.D.** and JULIETTE THARIAT, Ph.D.*** \\ The Department of Clinical Oncology, Faculty of Medicine, Sohag University, Sohag, Egypt* and \\ The Departments of Radiodiagnostics ** and Radiation Oncology***, Centre Antoine Lacassagne, \\ University Nice Sophia Antipolis, Nice, France
}

\begin{abstract}
Background: Obstructive Sleep Apnea (OSA) and L' hermite Sign (LS) are known but uncommon manifestations of various general and local illnesses both non malignant and malignant ones. Screening the PubMed for studies linking either one or both of these manifestations with Head and Neck Cancers (HNCs) treated by concomitant radio chemotherapy found that few studies reporting on LS in association with chemo rather than radiotherapy. Even fewer those studies that reported on OSA and, perhaps only one case report that described simultaneous incidence of both of these morbidities in one patient, that was the present case report.

Case Report: The authors describe a case of locally advanced head and neck squamous cell carcinoma treated with chemo followed by concomitant chemoradiotherapy and developed an early post treatment simultaneous occurrence of OSA and LS both of them got improved after vitamin supplement, steroid and, Continuous Positive Airway Pressure (CPAP) therapy.

Conclusion: This case highlights the importance of keeping the doses of neurotoxic chemotherapeutic drugs mainly cisplatin as low as possible when given concomitantly with radiotherapy in head and neck cancers also, the maximum dose to the spinal cord below 46 gray.
\end{abstract}

Key Words: Obstructive sleep apnea $-L^{\prime}$ hermite signChemo radiotherapy.

\section{Introduction}

DEFINITIVE treatment of Head and Neck Cancers (HNCa) generally comprises surgical intervention, Radiotherapy (RT), and chemotherapeutic agents [1].

OSA, is a relatively common sleep disorder manifested by recurrent attacks of partial or com-

Correspondence to: Dr. Ali M. Ali,

E-Mail: amali69eg@yahool.com plete collapse of the upper airway passages on sleeping [2]

The prevalence of OSA among patients with $\mathrm{HNCa}$ at baseline before initiating treatment is not well-known, but a high prevalence has been noticed after management by surgery and irradiation. RT leads to persistent edema of the mucosal lining, reduces elasticity and increases fibrosis, that consequently leads to poor pharyngeal constriction and may directly damage the skeletal muscles. Long lasting edema can in turn be exacerbated by the development of hypothyroidism after RT [1].

LS is a transient myelopathy appears as shocklike sensations from the neck down to the extremities, typically after flexion of the neck. It can be evoked by different factors including irradiation therapy which causes demyelination of axons and reduced speed of action potentials. It is reported to affect about $3.9 \%$ of Head and Neck $(\mathrm{H} \& \mathrm{~N})$ patients receiving Radiotherapy (RT). LS is usually reversible and develops at a median time of 3 months after a course of RT and persists for a median duration of about 6 months. The lowest Spinal Cord (SC) dose related to LS was reported to be at $38.2 \mathrm{~Gy}$. Patients ages higher than 52 year, those receiving accelerated $\mathrm{RT}$ and median volume of $14.15 \mathrm{~cm}^{3}$ of SC receiving total dose higher than 45Gy are all significantly associated with LS [3]

Cisplatin is a chemotherapeutic agent commonly used to treat different cancers. A well known toxic effect of cisplatin is sensory Peripheral Neuropathy $(\mathrm{PN})$. It is reported that after high cumulative doses of cisplatin $\left(>400 \mathrm{mg} / \mathrm{m}^{2}\right)$ an advanced stage of cisplatin induced PN may be accompanied by demyelinating syndrome with appearance of LS 
due most probably to injury of the posterior columns of the spinal cord, similar to that occurring in case of multiple sclerosis or subacute combined degeneration of the SC due to vitamin BI2 deficiency [4].

Screening the internet for publications addressing the sudden association between CCRT in $\mathrm{HNCa}$ patients and development of either OSA or LS showed rarity of such studies in contrast to those reporting on the association of these morbidities with in non malignant diseases.

To the best of our knowledge, this case report is the first one that describes the simultaneous incidence of both morbidities in a patient received CCRT for his head and neck cancer.

\section{Case Report}

A 50-year-old man presented to Center Antoine Lacasagne with 3-month history of right sided cervical lump. A history of smoking for $30 \mathrm{yrs}$ and regular alcohol consumption was found. No history of general medical or neurological illnesses. His BMI was 24.5. Biopsy revealed well differentiated Squamous Cell Carcinoma (SCC). Local and general examinations were unremarkable. Head and neck MRI and whole body work up were also free. Right modified radical neck dissection was done and one from 31 nodes was malignant. In less than one month, lower neck inflammatory sign suggesting early local recurrence with skin permeation developed. PET CT showed no other areas with abnormal uptake.A multidisciplinary panel decided three courses of TPF (docetaxel $75 \mathrm{mg} / \mathrm{m}^{2}$, cisplatin $75 \mathrm{mg} / \mathrm{m}^{2}$ and fluorouracil $\left.750 \mathrm{mg} / \mathrm{m}^{2} \mathrm{D} 1-4\right)$ to be followed by Concomitant Chemoradiotherapy (CCRT). Three dimensional radiotherapy (3D RT) plan was made aiming at delivering 50 Gray to the pharynx and uninvolved neck nodes then boost dose to neck nodes level 3 and 4 up to 66 Gray, all in conventional fractionation The maximum dose to the spinal cord was 46 Gray. Concomitant cisplatin at $100 \mathrm{mg} / \mathrm{m}^{2} \mathrm{D} 1,22,43$ was also given. Three month after completing his CCRT, the patient developed an electric shock-like sensation on neck flexion associated with sleep fragmentation and loud snoring. On local and neurological examinations, there was no obstructive pharyngeal edema nor any neurological deficits. Polysomnography showed an Apnea-Hypopnea Index (AHI) of 55 episode/hour with hypoxemia nadir of $82 \%$, an oxygen desaturation index of $-3 \%$. Dramatic improvement was noticed after treatment with Continuous Positive Airway Pressure (CPAP) therapy, vitamin supplementation (cobalamin + thiamin) and corticoids. With drop in AHI to 0.7 episode/ hour. Follow-up MRI 3-month post-treatment showed neither signs of myelitis nor of tumor. The patient was receiving levothyrox tablets for mild hypothyroidism and during 6 years of follow-up he has had no recurrence of cancer nor of such morbidities.

\section{Discussion}

OSA is being progressively recognized as an important cause of medical morbidity and mortality. The ensuing reduction of airflow often leads to acute disturbance in the process of gas exchange with recurrent arousals from sleep. When left without treatment, it causes excessive daytime sleepiness, cognitive disorders, reduced work performance, and decrements in health-related quality of life [2].

The Apnea-Hypopnea Index (AHI) is defined as the number of apneas or hypopneas per hour of sleep. Per the American Academy of Sleep Medicine Task Force, a score of $<5$ indicates no evidence of OSA, mild disease when $>5$ and $<15$, moderate severity when $\geq 15$ and $<30$, and severe disease when $>30[\mathbf{1 , 5}]$

From pathophysiological point of view, OSA is characterized by inability of the patient to have patent upper airway passage on sleeping, which can be caused by enlarged soft tissue such as the base of tongue and palate, narrowing of the pharyngeal space by anatomic abnormalities, or loss of function of the pharyngeal dilator muscles [6]

Our patient received chemotherapy including two drugs known to have neurotoxicity, cisplatin and docetaxel. The cumulative dose of cisplatin was $525 \mathrm{mg} / \mathrm{m}^{2}$ while that of docetaxel was 225 $\mathrm{mg} / \mathrm{m}^{2}$. Docetaxel was reported to be associated with $6 \%$ incidence of LS at doses $>200 \mathrm{mg} / \mathrm{m}^{2}[7]$, while cisplatin induced LS was reported after cumulative doses between 560 and $720 \mathrm{mg} / \mathrm{m}^{2}$ [8]

In analysis of our case, it seems that in absence of local causes of OSA and LS, absence of medical history for neuropathy (e.g., diabetes and hypertension), the relatively early onset both morbidities as well as the dramatic improvement attained with medical treatment and with CPAP, we postulate that, myelopathy induced by CT (primarily cisplatin) and by RT were the only players on the theater in a background of long history of smoking and alcohol consumption and more concern should be paid to the cumulative dose of cisplatin especially when given with RT. 


\section{Conclusion:}

Clinicians have to be aware of the relationship between OSA, LS and CCRT to the head and neck region and modification of the chemotherapeutic regimen as well as early effective treatment should be considered in order to prevent chronic progressive myelopathy.

\section{Disclosure of interest:}

The authors declare that they have no competing interest.

\section{References}

1- JESSICA ZHOU and SHRUTI JOLLY: Obstructive Sleep Apnea and Fatigue in Head and Neck Cancer Patients. Am. J. Clin. Oncol., 38: 411-4, 2015.

2- NARESH M. PUNJABI: The Epidemiology of Adult Obstructive Sleep Apnea Proc. Am. Thorac. Soc., 5: 13643, 2008.

3- V.E.M. MUL, J.M.A. De JONG, L.H.P. MURRER, et al.: Lhermitte sign and myelopathy after irradiation of the cervical spinal cord in radiotherapy treatment of head and neck cancer. Strahlenther Onkol., 188: 71-6, 2012.

4- TALI SIEGAL and NISSIM HAIM: Cisplatin-Induced Peripheral Neuropathy Frequent Off-Therapy Deterioration, Demyelinating Syndromes, and Muscle Cramps CANCER, 15: 1117-23, 1990.

5- RUEHLAND W.R., ROCHFORD P.D., O'DONOGHUE F.J., et al.: The new AASM criteria for scoring hypopneas: Impact on the apnea hypopnea index. Sleep, 32: 150-7, 2009.

6- MORRISON D.L., LAUNOIS S.H., ISONO S., et al.: Pharyngeal narrowing and closing pressures in patients with obstructive sleep apnea. Am. Rev. Respir. Dis., 148: 606-11, 1993

7- VAN DEN BENT M.J., HILKENS P.H., SILLEVIS SMITT P.A., et al.: Lhermitte's sign following chemotherapy with docetaxel. Neurology, 50 (2): 563-4, 1998.

8- WALTHER P.J., ROSSITCH E. Jr. and BULLARD D.E.: The development of Lhermitte's sign during cisplatin chemotherapy. Possible drug-induced toxicity causing spinal cord demyelination. Cancer, 1; 60 (9): 2170-2, 1987.

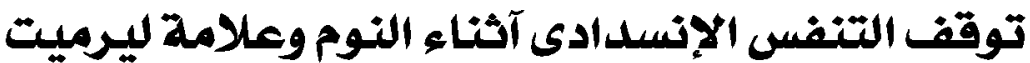 بعد العلاج الإشعاعى والكيماوى لسرطاء العان الرآس والرقية
}

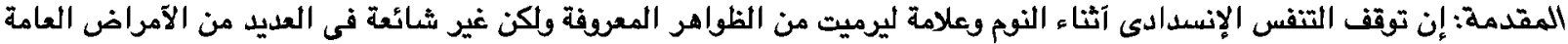

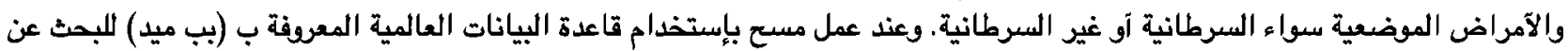

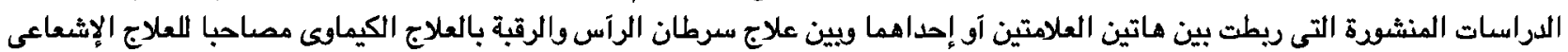

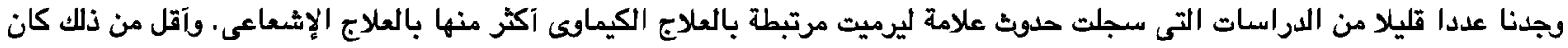

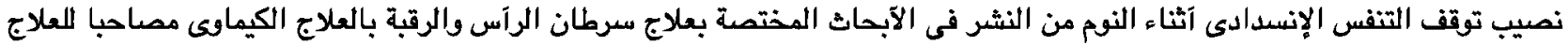

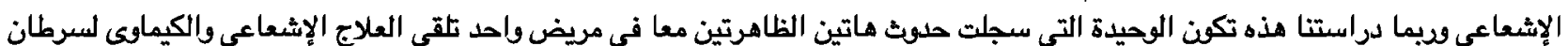 \\ في منطقة الرآس والرقبة. \\ توصيف الحالة: الباحثون يوثقن في هذه الدراسة خالة مريض يعانى من سرطان الخلايا الحرشفية فى منطقة الرآس والرقبة تم علاجه الراجيه

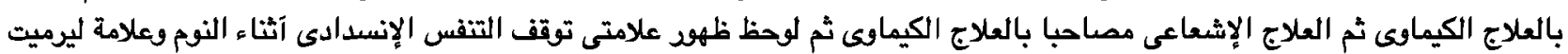

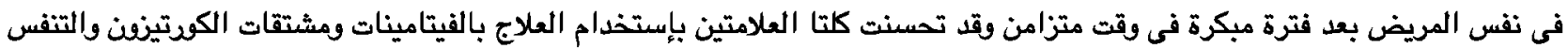

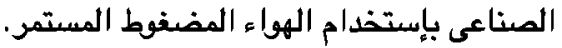

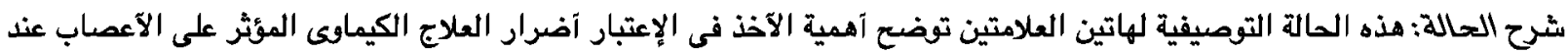

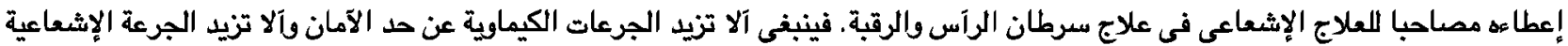

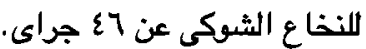

